\title{
Comentario a "Legalismo moral y tolerancia. Crónica de una muerte anunciada" de René González de la Vega
}

\section{Comment on "Moral Legalism and Tolerance. Chronicle of a Foretold Death" of René Gonzalez de la Vega}

Graciela Vidiella*

Recepción y evaluación de propuesta: 20/2/2014

Aceptación: 20/03/2014

Recepción y aceptación final: 22/6/2015

Resumen: Mi propósito es revisar los dos argumentos centrales que el autor elabora para sostener su posición. En ambos casos se llegará a la conclusión de que, desde una perspectiva liberal deontológica, la tolerancia es irrelevante. Tengo para mí que la reconstrucción propuesta se corresponde mejor con sistemas normativos jurídicos que con sistemas normativos morales. A mi modo de ver lo que permite a González de la Vega sostener tales argumentos es una determinada versión del liberalismo deontológico. Creo que es posible ser un deontologista moral y admitir una racionalidad imperfecta capaz de acoger las indeterminaciones y los dilemas.

Palabras Claves: tolerancia, deontologista moral, racionalidad.

Abstract: My purpose is to review the two central arguments that the author prepares to hold his position. In both cases it will come to the conclusion that, from an ethical liberal perspective, tolerance is irrelevant. My belief is that the proposed reconstruction better

* Universidad Nacional de La Plata / Universidad Nacional del Litoral, Argentina. E-mail: gravidiella@gmail.com 
corresponds to moral normative systems than to legal regulatory systems. In my view what allows Gonzalez de la Vega sustain such arguments is a particular version of deontological liberalism. I think it is possible to be a moral deontologist and admit an imperfect rationality capable of hosting the uncertainties and dilemmas.

Key words: tolerance , moral deontologist , rationality.

\section{Introducción}

La tesis central del artículo de René González de la Vega es que la tolerancia resulta inconsistente con la clase de razonamiento práctico sostenido por el liberalismo deontológico y que el modo de eliminar dicha inconsistencia es eliminar la tolerancia.

La primera sensación que tuve al leer el trabajo fue de desconcierto. La tolerancia es el corazón del liberalismo desde, por lo menos, los tiempos de John Stuart Mill; afirmar que resulta inconsistente con esta corriente es, al menos, osado. Cierto es que la tesis no pretende abarcar todo el liberalismo sino solo su vertiente deontológica. Sin embargo, quitar la tolerancia de teorías tales como las de Thomas Nagel, Ronald Dworkin y, fundamentalmente la de John Rawls, quien construyó con cuidadosa premeditación su liberalismo político sobre esta base, no es moco de pavo. Si la examinamos a la luz del equilibrio reflexivo, la tolerancia pasaría exitosamente el examen por ser una de las intuiciones más firmes de cualquier sociedad que posea una cultura pública liberal.

Sin embargo, una lectura más detenida me reveló un artículo de gran solidez argumentativa, que propone un verdadero desafío a un teórico del liberalismo deontológico.

Mi propósito es revisar los dos argumentos centrales que el autor elabora para sostener su posición. El primero de ellos se refiere a un conflicto que se le generaría a un agente en su propio conjunto de valores o principios morales ${ }^{1}$ al preguntarse si le corresponde ser tolerante

1 El autor utiliza alternativamente "valor" y "principios" sin especificar sus significados, de modo que parece emplearlos como sinónimos. Como se aclarará más adelante, una parte de mi réplica se basa en la distinción conceptual entre ambos términos. 
Comentario a "Legalismo moral y tolerancia. Crónica de una muerte..."

ante determinada acción de un tercero ("conflicto profundo"). E1 segundo alude a un conflicto que se le produciría a un agente entre sus reglas y/o principios morales y sus "convicciones éticas, estéticas, filosóficas, ideológicas, religiosas y demás clases" ("conflicto menos profundo"). En ambos casos se llegará a la conclusión de que, desde una perspectiva liberal deontológica, la tolerancia es irrelevante.

Hay dos rasgos del liberalismo deontológico que se tienen especialmente en cuenta: la prioridad moral que posee lo correcto o justo (las obligaciones) respecto de lo bueno y, en consecuencia, la justificación independiente que tienen los principios morales o de justicia respecto de los ideales de vida o de cualquier bien en particular (tal como, por ejemplo, pretende Rawls que pueden justificarse sus principios de justicia en Political Liberalism). El otro es la separación entre ética y moral y la prioridad absoluta que tienen las razones morales sobre cualesquiera otras. Según el autor es esta separación la que permite al liberalismo deontológico sostener la tolerancia (definida como ideal moral o propiedad disposicional o virtud de la justicia). Además, para que corresponda hablar de tolerancia deben cumplirse los siguientes requisitos: en primer lugar, que una convicción relevante - tanto moral como no moral pero basada en razones y no en gustos, deseos o emociones - sostenida por un agente haya sido lesionada por la acción de un tercero; en segundo lugar que el agente afectado tenga el poder de detener la acción y, finalmente, que por determinadas razones morales decida no hacerlo, es decir, tolerarlo.

Explicitado lo anterior, comienzo a tratar los dos argumentos objeto de mi comentario, empezando por el primer conflicto.

Supongamos que Pedro se siente ofendido porque una acción de Juan es contraria a alguna de sus convicciones morales y se pregunta si debe tolerarla o no. El procedimiento que debe seguir es revisar su convicción a la luz de algún principio —o un conjunto de principiosque cumpla con las condiciones exigibles a la racionalidad práctica moral: imparcialidad, universalidad, razonabilidad, reciprocidad (por ejemplo, el principio del no rechazo razonable de Scanlon, el principio de igual consideración y respeto, los tres principios formulados por Nino o, incluso, alguno de los principios y reglas postulados por la 
ética dialógica). Si la convicción de Pedro sale airosa del test, entonces no debe tolerar la acción de Juan; si, por el contrario, no pasa el test, la tolerancia tampoco tiene lugar: Juan está moralmente obligado a aceptar la acción de Pedro, a no impedirla, porque no existen razones válidas, objetivas, para rechazarla. Esto es, en un caso la tolerancia es moralmente inadecuada, por tanto no debe tener lugar, y en el otro, no es requerida porque no hay nada que tolerar. Estas son las conclusiones que corresponde inferir cuando se sostienen las tesis de esta corriente, que René González enumera así:

(1) Actuar correctamente significa actuar conforme a las obligaciones morales. Estas obligaciones son auto-impuestas (autónomamente aceptadas) y razonablemente creadas (sin considerar razones relativas al agente).

(2) Obedecer las normas morales no implica considerar las consecuencias (benéficas o perjudiciales) de nuestros actos.

(3) Los sistemas normativos tienen que ser completos y consistentes. Esta consideración lleva a sostener sistemas normativos monistas los cuales evitan problemas de incoherencias e inconsistencias.

(4) Las normas morales son inderrotables. Si queremos actuar moralmente, entonces, no puede haber ninguna otra consideración, valor o principio distintos a la moral y que derroten las normas que pertenecen a ese ámbito. Los agentes morales están categóricamente vinculados a las normas morales.

Por tanto - especialmente por la tesis (3) - el deontologismo moral no admite la posibilidad de dilemas morales ${ }^{2}$ porque introducirían un déficit epistémico en un sistema que, desde un punto de vista ideal, es concebido como completo y consistente. Así, una situación

2 Cierto es que González de la Vega reconoce que hay autores enrolados en el liberalismo deontológico que admiten la posibilidad de dilemas morales, pero considera que constituyen una minoría, de manera que, a su juicio, la posición dominante los excluye ya que el propósito de una teoría moral es guiar la conducta de las personas, lo que resultaría fallido si se reconoce la posibilidad de dilemas. 
Comentario a "Legalismo moral y tolerancia. Crónica de una muerte..."

dilemática en que se ve envuelto un agente es, en realidad, producto de un error de apreciación de la situación o un problema de consistencia entre normas, principios o valores morales; si se trata de esto último corresponde revisar el sistema para solucionar la inconsistencia.

En relación con el segundo conflicto, es decir, el que ocurre entre normas o valores morales y valores de otra clase, también concluye el autor que la tolerancia no tiene lugar porque se vuelve irrelevante. Para desarrollar este argumento alude a conflictos entre valores estéticos y morales y entre valores éticos y morales. Traeré a colación solo este último dado que es el más importante.

Tomemos el caso de un agente que tiene un conocido que padece una enfermedad terminal y ha decidido someterse a la eutanasia ${ }^{3}$ (legal en su país). Nuestro agente es una persona religiosa que piensa que la vida humana es sagrada y que solo Dios tiene derecho a disponer de ella. Se pregunta si debe tolerar esta práctica o si debe intentar impedirla por algún medio que encuentre a su alcance. Como en el ejemplo de Juan y Pedro, si examina el conflicto a la luz de la argumentación moral, lo resolverá moralmente, porque las razones morales tienen mayor jerarquía que las de cualquier otro tipo, por lo tanto la tolerancia no tiene lugar: o llega a la conclusión de que no debe actuar ante actos de eutanasia porque, examinada desde los principios, esta práctica no lesiona a ninguno, por lo cual el agente "debería eliminar de su sistema de valores" la sacralidad de la vida, o sí debe actuar oponiéndose porque, tras un cuidadoso examen, llega a la conclusión de que la eutanasia lesiona algún principio o norma de su sistema y, por tanto, es inmoral. Es decir, ninguna de las dos posibilidades hace lugar a la tolerancia: si la eutanasia no es inmoral no hay que tolerarla sino aceptarla, si lo es hay que rechazarla. En síntesis, las razones éticas (o religiosas, o metafísicas o estéticas) resultan derrotadas por las razones morales que tienen prioridad dado su carácter absoluto.

3 Adoptando la posición de R. Forst el autor asume que el aborto, la eutanasia y la manipulación genética constituyen un claro ejemplo de problemas éticos y no morales. Aunque no comparto esta posición, no la discutiré aquí. 
A mi modo de ver, lo que permite a González de la Vega sostener tales argumentos es una determinada versión del liberalismo deontológico, versión que no es la única posible - dudo, incluso, que sea la hegemónica-; pues algunos de los filósofos que se mencionan en el artículo, por ejemplo Carlos Nino y Thomas Nagel, no sostienen la totalidad de las tesis que se endosa a esta corriente. Tengo para mí que la reconstrucción propuesta se corresponde mejor con sistemas normativos jurídicos que con sistemas normativos morales. Pienso que las exigencias de la racionalidad práctica imparcial aplicables al orden moral deben ser más débiles que las aplicadas al orden jurídico ${ }^{4}$. En este último caso resulta plausible suponer una racionalidad perfecta o completa, pero en el primero lo encuentro mucho más problemático: aunque se sostenga una moral cognitivista, la indeterminación cognitiva y, por tanto, la racionalidad imperfecta es algo con lo que hay que contar si se pretende construir una teoría moral que, aunque suponga condiciones ideales, sea realista. Creo que es posible ser un deontologista moral y admitir una racionalidad imperfecta capaz de acoger las indeterminaciones y los dilemas ${ }^{5}$.

Basándome en estas consideraciones, analizaré los dos conflictos anteriormente apuntados sosteniendo que, de las cuatro tesis mentadas, un liberal deontológico necesita afirmar la primera y la cuarta, pero no así la segunda y la tercera; con ello espero mostrar que, después de todo, no es pertinente anunciar la muerte de la tolerancia. Para cumplir este propósito comenzaré por realizar algunas consideraciones en las que apoyaré mis argumentos.

González de la Vega no distingue entre valores y normas; cierto es que tampoco lo hacen muchos liberales deontológicos. Sin embargo, creo que es importante realizar la distinción si se pretende justificar

4 Sigo en esto a Habermas, J. Facticidad y validez, Madrid, ed. Trotta, 2008, págs. 557 y ss.

5 Una posición de este tipo es sostenida por ejemplo por Nino, C.S. Ética de derechos humanos, Bs.As. Paidós, 1984, págs.97 y ss; por Nagel, T. "War and Masacre", en Philosophy and Public Affairs, Vol. 1, No. 2 (Winter, 1972), págs. 123-144, e incluso por el mismo Rawls. 
Comentario a "Legalismo moral y tolerancia. Crónica de una muerte..."

una moral universalista. Según Habermas ${ }^{6}$, los valores expresan preferencias subjetivas o intersubjetivas, es decir, expresan nuestra propensión hacia aquellos bienes que obtenemos o realizamos mediante una acción orientada a un fin que, por una $\mathrm{u}$ otra razón, consideramos valioso; en este sentido tienen una orientación teleológica. Como bien mostró Max $\mathrm{Weber}^{7}$, no es posible justificar una jerarquía objetiva entre los valores porque se encuentran en tensión y compiten entre sí. Las normas, en contraste, reclaman una pretensión binaria de validez (válidas/inválidas) y una obligación incondicional y universal; además, no pueden contradecirse entre sí, sino que deben formar un sistema. No ocurre lo mismo con los valores, ellos admiten gradaciones: calificamos una película de mala, buena, regular, excelente; una herramienta de útil, medianamente útil o inútil; un rostro de bello, hermoso, feo, horripilante. A diferencia de lo que sucede con las normas y principios morales ${ }^{8}$, no es apropiado referirse a la consistencia o inconsistencia de un sistema valorativo; ni siquiera resulta adecuado el concepto "sistema valorativo" porque no pueden establecerse jerarquías entre los valores - excepto que se adhiera a posiciones metafísicas densas-. Por supuesto que en circunstancias particulares, ante algún conflicto de valores, los ponderaremos en base a algún criterio estético, ético, prudencial o el que corresponda al caso, pero esta ponderación es contextual y contingente.

No ignoro que la diferenciación entre valores y normas ha sido objeto de críticas $^{9}$. En su momento, Charles Taylor, Michel Sandel y otros comunitaristas emplearon estas críticas para descalificar

${ }^{6}$ Habermas, J. Op.cit, págs. 327 y ss.

7 Weber, M. "La ciencia como vocación", en Ensayos de sociología contemporánea II, Barcelona, Planeta-Agostini, 1985, págs. 79-116.

8 En general, utilizo "principios" para referirme a los principios básicos de un sistema de moralidad del que se derivan "normas" con menor grado de generalidad (aunque en algunos pasajes empleo ambos términos como sinónimos).

9 La crítica con mayor enjundia filosófica probablemente sea la realizada por Putnam (Putnam, H. y Habermas, J. Normas y valores, Madrid, Trotta, 2008). Desde una posición comunitarista fue efectuada entre otros, por Taylor, Ch, The Sources of the Self, Harvard University Press, 1989 y por Sandel, M. en Liberalism and the limits of Justice, Cambridge University Press, 1982. 
al liberalismo. Por mi parte no niego que las normas presupongan valores: "No se debe mentir" supone que la verdad se considera algo valioso, "Debe ayudarse a los necesitados", supone el valor de la solidaridad, etc., pero esto no significa que la distinción entre ambos esté errada. Creo que la diferenciación entre valores y normas le resulta necesaria a una ética universalista de naturaleza deontológica y, como espero mostrar, también lo es para dar cuenta del rol que le cabe a la tolerancia en la corriente del liberalismo que estamos considerando.

La segunda distinción que deseo traer a colación es la que se da entre moral positiva y moral crítica o reflexiva. La primera alude a las prácticas, reglas y creencias que orientan las conductas socialmente aceptadas - o bien por la mayoría, o bien por grupos o institucionesEs un conglomerado en el que se entremezclan consideraciones normativas y valorativas provenientes de las costumbres, muchas veces no compatibles entre sí, sobre todo en las heterogéneas sociedades contemporáneas. Por moral crítica o reflexiva ${ }^{10}$ se entiende el principio "último" o conjunto de principios "últimos" —según se trate de un sistema monista o pluralista- que permite inferir normas de menor grado de generalidad, y a la luz de los cuales es posible examinar los juicios provenientes de la moral positiva. Esto es, como resulta obvio, lo que hizo Kant en los dos primeros capítulos de la Fundamentación de la Metafisica de las Costumbres, y lo que hacen los liberales deontológicos contemporáneos como Gewirth, que propone un único principio, o Rawls, con sus dos principios de justicia o Nino con sus tres principios básicos. Esta distinción está de algún modo presente en la propuesta de Ernesto Garzón Valdez que González de la Vega menciona: el "sistema normativo básico" y el "sistema normativo justificante"; a este último pertenecen las razones morales que podrán justificar o descartar una creencia perteneciente al sistema básico cuando la tolerancia está en juego.

${ }^{10}$ Una distinción clara de ambos tipos de moral es establecida por Nino, C.S., op. cit, págs. 80 y ss y por Guariglia, O. Moralidad. Ética universalista y sujeto moral, Bs.As. FCE, 1996 págs. 11 y ss. 
Comentario a "Legalismo moral y tolerancia. Crónica de una muerte..."

La distinción entre moral positiva y moral reflexiva no debe confundirse, a mi entender, con la diferenciación entre ética y moral, a la que también alude González de la Vega y que, como enfatiza con razón, está presente en todas las propuestas deontológicas. $\mathrm{La}$ moral consiste en las obligaciones que tenemos con los demás, lo que pretendió recoger Kant con la pregunta: "Qué debo hacer", mientras que la ética está vinculada a ideales de vida, a los valores mediante los cuales orientamos la persecución de nuestros fines últimos y que se reflejan en la pregunta socrática: "¿De qué modo debe un hombre vivir su vida?".

Si Huckleberry Finn hubiera sido capaz de hacer una reflexión crítica sobre sus creencias morales, habría resuelto sin sentimiento de culpa el conflicto que se le presentó cuando los cazadores de esclavos fugitivos le preguntaron si no se había topado con $\mathrm{Jim}^{11}$; habría probablemente comprendido que su obligación era no entregar a Jim (esto fue lo que finalmente hizo, pero no por convicción moral sino porque lo ganaron sus buenos sentimientos). El conflicto que se le presentó a Huck fue producto de un déficit de racionalidad práctica, de una argumentación fallida. Distinto es el caso del estudiante que pidió consejo a Sartre respecto de si debía quedarse a cuidar a su madre, de quien era el único sustento y consuelo o partir a Inglaterra para unirse a las fuerzas de la Francia libre ${ }^{12}$. Aquí se presenta un conflicto que tiene el carácter de dilema moral. Encuentro que González de la Vega emplea "conflicto" y "dilema" como si se tratara del mismo concepto y que esto contribuye a reforzar su idea de que las teorías deontológicas no admiten dilemas morales - al menos, según afirma, no los admite el liberalismo deontológico preponderante- - Recurro a Guillermo Lariguet $^{13}$, un especialista en el tema - también citado por el autor - para diferenciar los dos conceptos. Para este filósofo lo que caracteriza a un dilema moral es la inexistencia de una respuesta correcta frente a dos cursos de acción alternativos, es decir, ambas

${ }^{11}$ Twain, M. Las aventuras de Huck, Bs.As, Losada, 1939, cap. XVI.

${ }^{12}$ Sartre, J.P. El existencialismo es un humanismo, Bs.As, Sur, págs. 28 y ss.

${ }^{13}$ Lariguet, G. y Martínez, D. Els dilemes morals, Barcelona, UOC, 2008. 
opciones parecen igualmente justificadas (o injustificadas) porque lo que se presenta es un caso de indeterminación racional. La segunda característica del dilema es la "pérdida moral": sea cual fuere la opción que se elija, se producirá un daño inevitable. Creo que el ejemplo de Sartre ilustra muy bien estos rasgos.

Por las consideraciones que acabo de hacer creo, a diferencia de René González, que el liberalismo deontológico puede acoger los dilemas morales ${ }^{14}$ siempre y cuando no asuma - como hacen, por ejemplo, Alchurrón y Bulygin ${ }^{15}$, que parecen ser la referencia principal empleada por el autor en relación con la exigencia de completitudla condición de la completitud como un requisito necesario de la racionalidad práctica.

Teniendo en cuenta estas opiniones sobre los dilemas y la distinción entre moral positiva y moral crítica no acuerdo con la siguiente afirmación: "resolver el dilema de la tolerancia equivaldría a tener que desechar un valor o una norma que consideramos de irremplazable trascendencia en nuestras vidas. Por tanto, tolerar podría tornarse en una conducta irracional de los individuos". Si se acepta la definición de dilema dada por Lariguet, creo que no corresponde hablar de un "dilema de la tolerancia".

Como sugerí antes, resulta más procedente considerar que los conflictos morales en sentido estricto - es decir, los que ocurren en el ámbito de la moralidad - son conflictos entre normas. Bajo esta óptica resulta factible que se resuelvan mediante una buena aplicación del razonamiento práctico, es decir, ejercitando la phronesis, o puede que se trate de un auténtico dilema. Si se da la primera alternativa no corresponde tolerar sino resolver a cuál de las normas o principios debe darse lugar. Supongamos que prometí a un amigo prestarle un dinero para comprar una bicicleta, pero otro amigo me pide un préstamo para arreglar el techo de su casa, cuyo mal estado es la causa de que, cuando

${ }^{14}$ Un ejemplo lo ofrece Nagel en el ya citado artículo "War and Masacre".

${ }^{15}$ Alchurrón, C. y Bulygin, E. "Deontic Truth and Values" Confr. Carlos Alchourrón y Eugenio Bulygin: en «Essays in legal theory in honor of Kaarle Makkonen» XVI, Oikeustiede, Jurisprudentia, 1983, pág. 27 y ss. 
Comentario a "Legalismo moral y tolerancia. Crónica de una muerte..."

llueve, el agua inunde la vivienda. No tengo suficiente dinero para cumplir con los dos. Consideremos la situación a la luz de un sistema monista, cuyo principio último es la igual consideración y respeto que merecen todas las personas. El cumplimiento de las promesas es una norma que puede justificarse fácilmente bajo ese principio; también lo es la obligación de ayudar a las personas con necesidades perentorias en la medida de las posibilidades del agente. Cualquiera sea la opción que elija incumpliré alguno de los dos principios. ¿Estoy ante un dilema? No lo creo, porque si tengo en cuenta las circunstancias y consecuencias específicas de la situación, lo más probable es que decidida procurar el dinero al amigo que debe arreglar la casa y me disculpe con el otro por no cumplir mi promesa, explicándole la situación. Las consecuencias implicadas por esta opción, hasta donde alcanzo a advertir, serían menos graves — no tendrían, en realidad, ninguna gravedad - que las que se producirían si dejo en la estacada a mi segundo amigo. A mi modo de ver, mi elección no produciría ninguna pérdida moral ${ }^{16}$. Un liberal deontológico no tiene por qué no tener en cuenta las consecuencias, y, cuanto más phronesis posea, mejor las evaluará y mejor actuará ${ }^{17}$.

Tampoco el que se enfrenta a un auténtico dilema moral tendrá nada que tolerar, solo le quedará actuar y aceptar con resignación la pérdida moral que, en este caso, sí ocurrirá inevitablemente.

Por tanto estoy de acuerdo con René González - aunque por otras razones - respecto del primer conflicto que propuso: cuando este se produce entre normas morales no cabe hablar de tolerancia desde el marco de una teoría deontológica.

${ }^{16}$ Tengo clara la objeción que se podría realizar a este planteo: la acción es incorrecta porque se está violando una norma. Quizá mi argumento podría mejorarse introduciendo el concepto de principios prima facie de Ross, aunque evitando el pluralismo intuicionista de este autor mediante algún criterio o regla de prioridad, pero no entraré aquí en esta compleja cuestión.

${ }^{17}$ No considero que el liberalismo deontológico sea incompatible con la idea de virtud. Para nombrar el ejemplo contemporáneo más ilustre, las virtudes políticas juegan un papel muy importante en la idea de Razón Pública tal como Rawls la expone en Political Liberalism. 
Paso a considerar el segundo, el que se da entre cuestiones morales y temas correspondientes a otras esferas de la racionalidad práctica.

Pongamos por caso que orienté mi vida a la luz de los "más altos" valores intelectuales y estéticos; esto me hizo, desde joven, considerar la filosofía, la literatura, y, en general, las disciplinas humanísticas como las actividades que más contribuyen a enriquecer la vida. Traté de inculcar estos valores a mi hija desde su infancia: hice que estudiara música y pintura, la llevé al teatro Colón y le enseñé a apreciar las obras de arte que se encuentran en el Prado, en el Louvre, en el Museo de Arte Moderno de Nueva York y en cuanto museo hayamos visitado en nuestros viajes. También la fui introduciendo en los grandes hitos de la literatura universal sugiriéndole lecturas acordes a su edad: Tom Saywer y El libro de la selva a sus diez años, algunos cuentos de García Márquez y de Cortázar a los catorce, Crimen y Castigo a los 16, todo ello intercalado con altas dosis de poesía. Sin embargo mi hija decidió estudiar la carrera de Contaduría, detesta la poesía, solo lee, de tanto en tanto, alguna novelita rosa de moda, la pintura la deja fría y la música clásica le aburre sobremanera; ama la cumbia y los cuartetos cordobeses, dos géneros que me resultan insufribles. Durante su adolescencia y primera juventud intenté reconducirla por la buena senda: apelé a razones, le hablé sobre la automodelación del carácter y sobre la conquista de la libertad, pero no obtuve ningún resultado positivo. Un día le espeté que era una superficial y una tilinga y le arrojé a la cara la siguiente pregunta: “iqué hice yo para merecer esto?" Me contestó que estaba harta de que me metiera en su vida, que los cuartetos de Beethoven que la obligaba a escuchar, porque yo los ponía una y otra vez mientras trabajaba en la computadora, le resultaban inaudibles, pero que ella tenía que encerrarse en su habitación y colocarse los auriculares para escuchar su música porque yo no la soportaba, que mi vida le parecía lo más gris y aburrido imaginable. Mi indignación y mi dolor se convirtieron en perplejidad cuando mi analista me dijo: "¿Qué le sugiere la palabra intolerancia"? Touché. Mientras caminaba de regreso a mi casa intenté razonar desde el moral point of view. La conclusión a la que llegué fue que mi hija no había violado ningún principio moral, que si yo la respetaba como persona autónoma no tenía ningún derecho 
Comentario a "Legalismo moral y tolerancia. Crónica de una muerte..."

a meterme en su vida, como tampoco tenía derecho a imponerle mis gustos musicales. Yo había actuado de manera intolerante, ese era mi vicio. Recordé a Aristóteles y su idea de que la virtud se adquiere ejercitándola. La verdad es que me costó bastante, pero creo que lo conseguí. Ahora soy yo quien se pone los auriculares para escuchar a Beethoven. Incluso le pregunto a mi hija por la última novela de Florencia Bonelli, escritora que la apasiona. Ella me resume el argumento; por supuesto que me parece una completa estupidez, pero no se lo digo, no por hipocresía sino para no herir sus sentimientos. Creo que me convertí en una persona tolerante. Ser tolerante significa aceptar que ella jerarquice sus valores de un modo diferente al mío, aún cuando las acciones orientadas por sus valores me desagraden o hasta me repugnen. En este caso mi sistema de moralidad me condujo a la conclusión de que no tengo ningún argumento moral para impedir que mi hija guíe su vida según sus propias convicciones éticas. Dado que ella no quebró ningún principio moral no encuentro ahora ninguna razón imparcial, universal, etc. para censurar sus actos. Pero no estoy de acuerdo con René González respecto de que la tolerancia deja de ser requerida. Si bien, para ponerlo en los términos utilizados que emplea aludiendo a Garzón Valdés, podemos decir que la norma de mi sistema superior derrotó la norma de mi sistema normativo básico: "No debo dejar que mi hija oriente su vida por valores inferiores", esto no implica que la tolerancia sea irrelevante: una acción inmoral no puede tolerarse, pero una acción que hiera mis valores éticos, estéticos, etc. sí requiere ser tolerada, porque me seguirá disgustando, ofendiendo o incluso dando asco. En lo que sí coincido con el autor es en que la tolerancia resulta mucho mejor cumplida entendiéndola como virtud que como principio.

Hasta aquí intenté ponerme en la piel de un liberal deontológico para replicar los argumentos de René González. Concluiré esbozando mi propia posición, la que, tengo la impresión, no se encuentra tan distanciada de la suya. Como acabo de afirmar, coincido plenamente con que la tolerancia es una virtud cuyo ejercicio, como el de toda virtud, requiere de sensibilidad moral para captar el contexto en el que correspondería aplicarla. Requiere que se tenga registro de las 
personas involucradas, que se comprenda cuál es el fin de la acción que corresponde llevar a cabo y que se conozcan los medios para lograrlo, que sepan sopesarse los bienes y los males que están en juego, en fin, requiere de todas las instancias que hacen a un razonamiento práctico prudente. Pero no creo que la ética de la virtud deba presentarse como una alternativa a las éticas deontológicas; más bien considero que las virtudes constituyen un complemento necesario de aquellas para dar cuenta, entre otras, de las importantes cuestiones referidas a la motivación moral. También pienso que las éticas exclusivamente legalistas son bastante infecundas y me parece que se ha insistido demasiado con ellas en muchas de las propuestas contemporáneas. Pero también estoy convencida de la validez que posee el enfoque del universalismo ético y del punto de vista crítico e imparcial que demanda una moral posconvencional. A mi modo de ver, las cuestiones vinculadas con la justicia, sobre todo las concernientes a los derechos morales y a los derechos humanos en particular, constituyen uno de los temas más importantes de la ética y no creo que puedan ser bien tratadas si se abandona la perspectiva deontológica. En este sentido, una teoría ética debería compatibilizar el punto de vista legalista de las normas con el punto de vista centrado en el agente moral. Después de todo, la pregunta socrática es tan importante como la kantiana.

\section{Bibliografía}

Alchurrón C. \& Bulygin E. "Deontic Truth and Values" Confr. Carlos Alchourrón y Eugenio Bulygin: en Essays in legal theory in honor of Kaarle Makkonen XVI, Oikeustiede, Jurisprudentia, 1983.

Guariglia, O. Moralidad. Ética universalista y sujeto moral, Bs.As, FCE, 1996. Habermas, J. Facticidad y validez, Madrid, ed. Trotta, 2008.

Lariguet, G. y Martínez, D. Els dilemes morals, Barcelona, UOC, 2008. Nagel, T. "War and Masacre" en Philosophy and Public Affairs, 1, 2, 1972.

Nino C.S. Ética de derechos humanos, Bs.As, Paidós, 1984.

Putnam, H. y Habermas, J. Normas y valores, Madrid, Trotta, 2008.

Sandel, M. Liberalism and the limits of Justice, Cambridge, Cambridge University Press, 1982. 
Comentario a "Legalismo moral y tolerancia. Crónica de una muerte..."

Sartre, J.P. El existencialismo es un humanismo, Bs.As, Sur.

Taylor, Charles. The Sources of the Self, Cambridge, Harvard University Press, 1989

Twain, M. Las aventuras de Huck, Bs.As, Losada, 1939.

Weber, M. "La ciencia como vocación", en Ensayos de sociología contemporánea II, Barcelona, Planeta-Agostini, 1985. 
